\title{
A CONTINUIDADE/DESCONTINUIDADE NOS CURRÍCULOS DE EDUCAÇÃO INTEGRAL: REFLEXÕES A PARTIR DO PROGRAMA ENSINO MÉDIO INOVADOR EM CAMPINA GRANDE/PB
}

\author{
CONTINUITY/DISCONTINUITY IN THE CURRICULA FOR INTEGRAL EDUCATION: \\ REFLECTIONS FROM THE INNOVATIVE HIGH SCHOOL PROGRAM IN CAMPINA \\ GRANDE/PB
}

\author{
LA CONTINUIDAD/DISCONTINUIDAD EN LOS CURRÍCULOS DE EDUCACIÓN \\ INTEGRAL: REFLEJOS A PARTIR DEL PROGRAMA DE LA ENSEÑANZA MEDIA \\ INNOVADORA EN CAMPINA GRANDE/PB
}

Francisca Pereira Salvino ${ }^{1}$

${ }^{1}$ Doutora em Educação pela UFRJ. Docente do Departamento de Educação da Universidade Estadual da Paraíba (UEPB), Campina Grande, PB, Brasil.

Resumo: As múltiplas "vozes" que dialogam neste texto objetivam analisar continuidades e descontinuidades na proposta de currículo para educação integral, evidenciadas com a reestruturação do Programa Ensino Médio Inovador (Pro-EMI), a partir de 2016. Decorre de pesquisa qualitativa nos moldes da análise documental, tomando como referência empírica escolas de Ensino Médio do município de Campina Grande/PB. Argumenta-se que o neoliberalismo, mais do que uma doutrina político-econômica, é um discurso com forte penetração na vida cotidiana, contudo as escolas não são meros espaços de reprodução de políticas neoliberais, mas microespaços de política cultural, nos quais textos/documentos são ressignificados e recontextualizados. Conclui que as continuidades e as descontinuidades evidenciadas no Programa situam-se no complexo processo de reordenação do capitalismo que, favorecido pelo avanço das tecnologias de informação e comunicação, intensifica as parcerias público-privadas, constituindo redes de políticas que dão novos sentidos à gestão da educação e do currículo, bem como às relações (globais/locais), às disputas e aos mecanismos de regulação em torno do currículo de educação integral.

Palavras-chave: Currículo; Educação integral; Redes de política.

Abstract: The multiple "voices" that dialogue in this text aim to analyze continuities and discontinuities
in the curricular proposal for integral education, evidenced with the restructuring of the "Programa
Ensino Médio Inovador" (innovative High School Education Program) - Pro-EMI, from 2016 on. It is
the result of the qualitative research, in the form of documentary analysis, taking high schools in
the city of Campina Grande, PB as an empirical reference. It is argued that neoliberalism is more
than a political-economic doctrine; it is a discourse that pervades everyday life. Schools are not
mere spaces of reproduction of neoliberal policies, but micro spaces of cultural politics, in which
texts and documents are re-signified and re-contextualized. It is concluded that the continuities and
discontinuities evidenced in the Program lie in the complex process of reordering capitalism, which,
favored by the advances in information and communication technologies, intensifies public-private
partnerships, forming networks of policies that give new meanings to the management of education 
and curriculum, as well as (global and local) relations, disputes, and regulatory mechanisms around the comprehensive education curriculum.

Keywords: Curriculum; Integral education; Policy networks.

Resumen: Las múltiples "voces" que dialogan en el texto, tienen por objetivo analizar las continuidades y discontinuidades en la propuesta de los planes de estudios para la enseñanza integral, evidenciados con la reestructuración del Programa de la escuela secundaria Innovadora (Pro-EMI), desde 2016. Son resultados de una investigación cualitativa en la forma de análisis documental, tomando como referencia empírica escuelas de la enseñanza secundaria de la ciudad de Campina Grande/PB. Se argumenta que el neoliberalismo es más que una doctrina política económica, es un discurso con fuerte presencia en la vida a diario, sin embargo, las escuelas no son solo espacios de reproducción, pero micro espacios de la política cultural, en los cuales textos/documentos son para recontextualizarse y resinifica. Concluye que las continuidades y discontinuidades identificadas en el Programa están ubicados en el complejo proceso del capitalismo que, favorecida por el adelanto de las tecnologías de la información y comunicación, intensifica las asociaciones público-privadas, constituyendo las redes de políticas que dan un nuevo significado a la gestión de la educación y del currículo, así como las relaciones (globales/locales), a las disputas y mecanismos reguladores alrededor del currículo de educación integral.

Palabras clave: Currículo; Educación integral; Redes de política.

\section{INTRODUÇÃO}

"Tudo aquilo parecem desenhos, mas dentro das letras estão vozes Cada página é uma caixinha infinita de vozes" (COUTO, 2015)

O excerto em epígrafe remete-nos a uma salutar reflexão acerca de textos/documentos como representação de múltiplas "vozes", que ecoam das posições de sujeitos em diferentes tempos e espaços, de áreas de conhecimentos, de disputas, jogos e arranjos políticos em torno do currículo. Nesse sentido, textos/documentos definidores e indutores de política educacional, portanto, curricular necessitam ser interpretados a partir da consideração de processos de recontextualização e ressignificação, que ocorrem ao transitarem de um contexto a outro. Assumo, portanto, uma abordagem pós-crítica, entendendo-a como mais potente para pensar o neoliberalismo não apenas como doutrina político-econômica, mas como discurso com forte penetração na vida cotidiana, sem o qual as políticas não são implementadas. Isto não significa negar o Estado liberal ou Estado de direito. Significa que qualquer projeto de política curricular se constitui no âmbito de um quadro de incertezas, que dissolve "a possibilidade de uma intervenção programada, com projeto definido a despeito do jogo político" (LOPES, 2014, p. 58). Significa considerar que as comunidades escolares e seus sujeitos participam desse jogo com menor ou maior poder de intervenção a depender da correlação de forças.

Nesse sentido, textos/documentos são representações de políticas como complexos que envolvem constrangimentos e recontextualizações (MAINARDES, 2006) que são decididas, em grande medida, em contextos nacionais e ou internacionais, exercendo maior influência, produzindo ideias centrais, discursos e proposições mais facilmente hegemonizáveis. Todavia, ainda que entendamos que tais contextos sejam privilegiados como definidores e indutores 
de políticas curriculares, não devemos desconsiderar que são nos contextos de práticas que as políticas tomam forma, são implementadas e produzem-se efeitos/resultados desejados ou não pelas elites políticas que as projetam. Isto abre espaço para se pensar que, no campo do currículo, existe uma pluralidade de grupos em disputa, o que coloca as escolas na condição de microespaços de política, bem como as pessoas que neles atuam como sujeitos de política, portanto capazes de atuar e influenciar nas decisões, fazendo com que as políticas não sejam apenas o que o Estado e ou as autoridades políticas querem que elas sejam.

Sem descuidar da ambivalência e das assimetrias das relações de poder, da posição privilegiada do contexto de influência, este artigo objetiva analisar o currículo de educação integral a partir de continuidades/descontinuidades do Programa Ensino Médio Inovador (Pro-EMI), evidenciadas a partir de 2015, tomando como referência empírica escolas de Ensino Médio do município de Campina Grande/PB. Resulta de uma pesquisa qualitativa, nos moldes da análise documental, com recurso de entrevistas e questionários, e tendo como referência teórica principal os estudos acerca de redes políticas desenvolvidos por Stephen Ball (2004; 2014) e a Teoria do discurso de Ernesto Laclau e Chantal Mouff (2015).

\section{Mudanças no CURRículo de educação integral para o Ensino MÉdio E REDES DE POLÍtICA}

O Ministério da Educação (MEC) do Brasil, no rol de proposições contidas no Plano de Desenvolvimento da Educação (PDE), reestruturou, em 2007, a política de educação integral, idealizando-a em dois programas, a saber: Programa Mais Educação (PME), voltado ao Ensino Fundamental; e Programa Ensino Médio Inovador (Pro-EMI), voltado ao Ensino Médio. Ambos financiados com recursos do Fundo Nacional de Desenvolvimento da Educação (FNDE), do governo federal, repassados às escolas por meio do Programa Dinheiro Direto na Escola (PDDE).

O PDE, por sua vez, tem sua gênese no "Movimento Compromisso todos pela educação" lançado à sociedade em 2006, com pretensões a consolidar um amplo pacto social entre Estado, empresas privadas (com e sem fins lucrativos) e sociedade civil em defesa da educação. Segundo Shiroma, Garcia e Campos, (2011), a partir de então, esse movimento rapidamente ganhou adesões, ampliando o número de empresários, intelectuais, universidades, agências midiáticas, sindicalistas, dentre outros, dispostos a, juntamente com o MEC, corroboraram a sinergia necessária à busca de soluções plausíveis para a grave crise da educação. Dessa forma, "mantém-se, por um lado, estreitamente vinculado à esfera governamental, e por outro, assume uma posição de vigilância sobre as ações desta última, cumprindo os preceitos que anuncia para todos: responsabilização e controle social" (SHIROMA, GARCIA E CAMPOS, 2011, p. 231).

De modo geral, a relação entre público-privado na gestão das políticas públicas sempre foi turva, inclusive porque em qualquer projeto societário o Estado e os seus poderes são exercidos por "agentes" privados, que frequentemente atuam conforme uma lógica patrimonialista como se os mandatos públicos significassem a posse dos bens públicos. No caso do Brasil, desde a chegada da Companhia de Jesus, que primeiro organizou algum tipo de educação formal 
(seminários, escolas catedralícias, monastérios), as ações foram parcialmente financiadas com recursos da Monarquia portuguesa e da filantropia local, o que logo se apresentou como negócio lucrativo. O que se torna diferente nas primeiras décadas do século XXI é a abrangência; a proliferação; a hegemonia acerca da filantropia como negócio e como estratégia viável à qualidade da educação, por parte de governantes, empresários e comunidades (estudantes, parentes e outros). Isto torna as relações, bem como as fronteiras entre público e privado, ainda mais imprecisas e conturbadas. Diferentemente, por exemplo, da segunda metade do século XX, quando o consenso foi de que o Estado tanto nas versões liberais, Keynesianas ou socialistas, seria o grande responsável pela universalização da Educação Básica, por se tratar de um direito de todos os cidadãos e cidadãs, indistintamente.

Nas décadas mais recentes, mesmo governos ditos de "esquerda", como Luiz Inácio (20022010) e Dilma Rousseff (2011-2014) no Brasil, e Michele Bachelet (2006-2010 e 2014-2018) no Chile, adotaram políticas de privatização com bastante ênfase. Croso e Magalhães (2016) mapearam a situação da privatização (endógena e exógena) da educação na América Latina e no Caribe, categorizando os países conforme três níveis de privatização. No primeiro grupo, Argentina, Bolívia, Brasil, Colômbia, Equador, México e República Dominicana, que permitem mecanismos de concessão de escolas públicas para a iniciativa privada, compra de vagas no setor privado, ou transferência de subsídios públicos para a educação particular, mesmo que estabelecendo critérios para tal acordo. O segundo composto por Nicarágua e Costa Rica, engloba aqueles cujos, ao menos no âmbito legal, tais critérios não são estabelecidos. $O$ terceiro inclui os casos mais extremos, em que a legislação não apenas permite, mas também alenta ao setor privado a aumentar sua participação na oferta educativa, e para isso prevê a transferência de recursos públicos, como Chile, Guatemala, Honduras, Paraguai e Peru. "O caso chileno é paradigmático, já que a Lei Geral de Educação (LOE, 2009) define o financiamento compartilhado do sistema educativo" (CROSO e MAGALHÃES, 2016, p. 24).

Além da privatização endógena e exógena, o mapeamento considerou o que Ball e Youdell (apud CROSO e MAGALHÃES, 2016) chamam de privatização da política ou governança corporativa. Esse conceito refere-se à participação direta ou indireta de representantes do setor privado e da indústria da educação na definição do debate e da agenda pública educativa em todos os âmbitos. Essa influência é derivada da criação de redes de relações sociais entre políticos, funcionários públicos e empresários. Esse nível de privatização estabelece interconexões entre sujeitos, elementos e instituições, compondo redes políticas que se expandem em escala local/global.

Como analisa Ball (2014, p. 37), uma das características dessas redes de políticas é reafirmar o papel do Estado, mas em uma nova forma e com novas modalidades, envolvendo uma mudança na noção de "governo" para governança, ou seja, de burocracia para redes, de Estado prestador de serviços para contratante. Nessa perspectiva, esse modelo de gestão em rede, denominada de "governança", que se processa estabelecendo redes que interconectam diferentes sujeitos (pessoas, instituições, empresas e outros), em diferentes espaços e em diferentes escalas, normalmente extrapolando os limites dos entes federados (União, Estados e Municípios), ou seja, os limites do Estado-nação. Este se mantém, todavia, mudam suas 
formas de intervenção e seus dispositivos de controle e regulação, uma vez que fatores como capital financeiro, crime organizado, influência de organismo internacionais e redes sociais alteram sobremaneira seu poder de decisão e ação.

Nesse cenário, a governança em redes é entendida como marca da atual fase de desenvolvimento do capitalismo, denominada por Ball (2014) de neoliberalismo roll-out, caracterizado pela construção e pela consolidação proposital de formas de Estado neoliberalizadas, que além de governança, consolidam novas formas de relações e regulação, tanto nos macroespaços da política, quanto nos micros, ou seja, na vida cotidiana, no interior das instituições.

Como analisam Lima Júnior e Almeida (2015, p. 116), "[...] a governança relaciona-se com uma condição de não restrição conceitual, com contextualizações dinâmicas em termos de princípios e bases constitutivas, que são, simultaneamente históricas, sociais e subjetivas". Para os autores, potencializada pelas Tecnologias de Informação e Comunicação (TIC), a governança tem como fundamento principal a própria condição humana, que nos faz geral na espécie e particular em cada sujeito. Tem como fundamento também uma perspectiva relativista e, consequentemente, "um saber auto expressivo de cada sujeito para manter-se enquanto uma posição ativa, ontológica e existencial, nesta condição geral simbólica, social e histórica" (LIMA JÚNIOR e ALMEIDA, 2015, p. 117). Esses autores afirmam que, para além do efeito lógico-abstrato de natureza científica e filosófica, a governança passa a referir-se a padrões de articulação e cooperação entre atores sociais e políticos, bem como a arranjos institucionais que coordenam e regulam transações dentro e por meio do sistema econômico. Incluem-se, ainda, mecanismos tradicionais (partidos, grupos de pressão, sindicatos e outros), redes sociais informais, relações não necessariamente hierarquizadas e associações de diversos tipos, inclusive passíveis de prescindir das ações do Estado. Isto tende a influenciar as decisões políticas, seus métodos, discursos e resultados.

Esses mecanismos afetam as formas da democracia, desestabilizando as formas de hegemonia e ressaltando "a impossibilidade da regulação total ainda que isto não a torna menos efetiva e o que chamamos de política é exatamente a busca pela regulação em maior ou menor grau, uma vez que a luta por hegemonia é a luta pelo controle dos sistemas de significação" (LOPES e MACEDO, 2011, p. 94). Assim, as formas de identificação/diferenciação dos sujeitos vão se delineando por meio de práticas articulatórias, das quais podem emergir cadeias de equivalências entre identidades antagonistas. Nessa direção,

As duas condições de uma articulação hegemônica são: a presença de forças antagonísticas e a instabilidade de fronteiras que as separam. Somente a presença de uma vasta área de elementos flutuantes e a possibilidade de sua articulação a campos opostos - que implica uma constante redefinição destes últimos - constituem o terreno que nos permite definir uma prática como hegemônica. Sem equivalência e sem fronteira, é impossível falar estritamente de hegemonia (LACLAU e MOUFF, 2015, p. 215).

Nessa perspectiva, a luta hegemônica se desvincula da ideia de identidade de classe, da possibilidade de fixação de sentidos definitivos, da presunção de identidades e democracia plenamente constituídas, uma vez que seus horizontes estão sempre a se deslocar, a deslizar para outros sentidos e outras formas de organização. Assim, a ideia de formação de "identidade plena" (integral), para uma sociedade ou democracia plenamente constituída (utopia), consiste 
numa necessidade e numa impossibilidade, uma vez que os sentidos são contingenciais, históricos e culturalmente situados. Por vezes, os significados de currículo para educação integral delineados nessas duas primeiras décadas do século XXI vão sendo instituídas por meio de redes de política, mas não estão postos em definitivo, nem são totalmente determinados. Nessa linha de pensamento,

Cada 'nova definição' não é apenas uma nova forma de descrever o objeto currículo, mas parte
de um argumento mais amplo no qual a definição se insere. A 'nova definição' se posiciona,
seja radicalmente contra, seja explicitando suas insuficiências, em relação às definições
anteriores, mantendo-se ou não no mesmo horizonte teórico delas. Esse movimento de
criação de novos sentidos para o termo currículo, sempre remetendo a sentidos prévios
para de alguma forma negá-los ou reconfigurá-los (LOPES e MACEDO, 2011, p. 19).

Ademais, faz-se necessário lembrar que políticas, programas e projetos curriculares mudam com os governos, os interesses, as demandas e as lutas sociais, mas não anulam toda a configuração anterior. Ocorre uma ressignificação, na qual determinados elementos e aspectos são continuados e outros descontinuados, salientando-se, como faz Saviani (2008), que no caso brasileiro as descontinuidades das políticas educacionais são tão frequentes e descompromissadas que, historicamente, tornaram-se um entrave à consolidação das políticas, ao direito à educação de qualidade.

\section{SITUANDO A PESQUISA: PROCEDIMENTOS, SUJEITOS E CAMPO EMPÍRICO}

A pesquisa de que trata este artigo dá continuidade a estudos sobre educação integral iniciados em setembro de 2013 com um projeto de extensão, cujo objetivo foi contribuir com a implementação do "macrocampos Integração Curricular" numa das escolas que havia aderido ao Programa Ensino Médio Inovador (Pro-EMI). Macrocampos são campos de conhecimento e atividades orientados pelo MEC para inovar, redesenhar e tornar mais atrativo o currículo do ensino médio (BRASIL, 2009), que nesse programa deve ser trabalhado com um mínimo de 7 horas diárias de atividades, ou seja, em tempo integral.

Mais recentemente, envidamos esforços com a pesquisa "A (des)continuidade das políticas curriculares para educação integral em Campina Grande/PB", que teve como objetivo analisar as alterações ocorridas nos programas 'Programas Mais Educação' (PME) e Pro-EMI a partir de janeiro de 2015, quando Dilma Rousseff deu início ao segundo mandato como presidente da república, prometendo (desde a campanha eleitoral) inovações para a educação, especialmente para o ensino médio. Dava mostras de que o Pro-EMI não seria prioridade no replanejamento das políticas, bem como assumia que a economia do país entrava em recessão e que os recursos haviam se tornado escassos, deliberando um incisivo corte nas verbas da educação na ordem $\mathrm{R} \$ 10,6$ bilhões no referido ano (uma redução de $\mathrm{R} \$ 109$ bilhões para $\mathrm{R} \$$ 98 bilhões, aproximadamente) (TOKARNIA, 2015). Além disto, um processo de impeachment em agosto de 2016 destituiu Dilma Rousseff, substituindo-a pelo seu vice, Michel Temer Lulia. A partir de então, o MEC promove uma série de alterações na política educacional e em diversos dos seus programas, dentre eles o Pro-EMI.

Esse Programa foi instituído pela Portaria no 971/2009 (BRASIL, 2009), compondo o Plano de Desenvolvimento da Educação (PDE) e o Plano de Aceleração do Crescimento (PAC). Trata-se de 
uma proposta curricular, pautada na intersetorialidade; no currículo integrado a ser construído (redesenhado) pelas comunidades escolares; com oito macrocampos com ênfase na iniciação científica, atividades culturais, artísticas e esportivas dos quais três seriam obrigatórios e dois eletivos, ofertados em escolas com as melhores infraestruturas das comunidades; formação continuada dos professores e remuneração (gratificação de R $\$ 600,00$ ) para dedicação exclusiva à escola; verbas complementares advindas do Fundo de Desenvolvimento da Educação (FNDE) repassadas por meio do Programa Dinheiro Direto na Escola (PDDE) para compra de materiais e equipamentos necessários às atividades pedagógicas. Ainda que essa gratificação seja insuficiente e a formação continuada questionável, criou-se uma situação mais apropriada do que o PME, cujos macrocampos deveriam ser ofertados por meio de trabalho voluntário e sem exigência de formação pedagógica.

Embora o Pro-EMI tenha sido lançado em meio à política de pactuação/parceirização do governo de Luís Inácio Lula da Silva, ele tinha como objetivo central garantir autogestão e autonomia às comunidades escolares no processo de redesenho curricular, inclusive para definir parcerias. Como o Programa mantém financiamento e gestão públicos, entendo que não se configura como governança em rede.

O Pro-EMI foi duramente afetado pelo corte de verba de janeiro de 2015, tendo suas verbas atrasadas por vários meses. Após o impeachment, um agravante foi a aprovação da Proposta de Emenda Constitucional no 55 (ou 241, conforme a casa legislativa) pelo Senado Federal, praticamente congelando as despesas do Governo Federal por até 20 anos. A medida foi alardeada pelo governo como necessária à contenção de gastos; redução da dívida pública; retomada do crescimento econômico e saída da recessão iniciada em 2014 e que se estendeu até 20171. Além disso, editou a Medida Provisória no 746/2016, que reformulou o Ensino Médio, convertida na Lei no 13.415/2017 (BRASIL, 2017); reestruturou o PME e o Pro-EMI, ocasionando uma descontinuidade na política e no currículo de educação integral. A edição da MP motivou protestos, ocupação de escolas por estudantes² que chegaram a durar meses e outras manifestações, sob a alegação de que o governo excluirá as comunidades escolares do debate, o que o fez retroceder em várias das suas proposições.

Os fatos demonstram que a política educacional necessita ser interpretada em sua interlocução com os contextos de influência (onde as políticas são decididas, por influência nacionais e internacionais), aqueles em que os conceitos se tornam centrais e os discursos se hegemonizam, visando legitimar determinadas intervenções; com demandas da sociedade mais amplas; com o que acontece no interior das escolas. Ainda que se entenda que tais contextos sejam privilegiados como definidores e indutores de políticas curriculares, eles conduzem à produção de textos/documentos coletivos, que como tais "são produtos de acordos realizados em diferentes esferas, envolvendo, inclusive, a troca constante de sujeitos autores" (LOPES e MACEDO, 2011, p. 259). Isto abre espaço para ações em outros contextos e para gerar efeitos/resultados variados.

Segundo Ball (2004), isto não significa que os sujeitos autores participem da mesma forma, nem que tenham suas "vozes" e posições aceitas/legitimadas com o mesmo vigor. Significa que "há uma pluralidade de grupos em disputa" em diferentes contextos, o que 
coloca as escolas na condição de microespaços de política, bem como as pessoas que neles atuam como sujeitos de política, portanto capazes de atuar e influenciar nas decisões, fazendo com que as políticas não sejam apenas o que o Estado e ou as autoridades políticas querem que elas sejam. De outro modo, profissionais e estudantes seriam apenas massa de manobras, seres inertes e passivos e o currículo seria uma reprodução unilateral, o que não faz mais sentido desde os anos de 1900, quando teóricos como Dewey e Kilpatrick (apud TEIXEIRA, 1967) reconhecem a educação como processo do qual os estudantes/aprendizes participam ativamente. A vasta obra de Freire, das quais destaco Pedagogia da Autonomia (1996) e Pedagogia da Indignação (2002), a qual assevera que a educação não se reduz à transmissão de conhecimento, mas se constitui em instrumento de transformação social. No campo do currículo, Giroux (2002) defende a cultura e o conhecimento popular como base para o currículo numa perspectiva emancipatória, entendo-o como campo de política cultural. Nessa linha, temos Corazza (1997) e Lopes e Macedo (2011), que entendem o currículo como campo de produção de sentidos e significados culturais.

Sem descuidar das assimetrias das relações de poder e da posição privilegiada dos contextos de influência, recorremos às escolas não como meras reprodutoras de políticas neoliberais, mas como contextos de prática, de implementação destas, que são decisivas para as políticas locais, nacionais e globais. A partir dessa prerrogativa, tomamos como campo empírico duas escolas estaduais de Ensino Médio da cidade de Campina Grande/PB, as quais adotaram ao Pro-EMI de 2012 a 2016. Contribuíram com a pesquisa profissionais da $3^{a}$ Gerência Regional de Ensino do Estado da Paraíba (sede em Campina Grande, mas vinculados à Secretaria Estadual de Educação em João Pessoa), que é o órgão responsável pela gestão administrativa e pedagógica do Programa. Essas instituições são identificadas como: i) E. E. Ensino Médio 1; ii) E. E. Ensino Médio 2; iii) 3a GRE/PB.

A pesquisa contou com a colaboração de quatro profissionais, sendo dois do gênero masculino e duas do feminino; um participante e uma participante que atuavam na coordenação dos projetos nas referidas escolas; um técnico administrativo da $3^{a}$ GRE/PB e uma excoordenadora do Pro-EMI na $3^{a}$ GRE/PB. Para manter o sigilo, eles e elas serão identificado/as apenas pelo setor ou função de atuação, conforme o Quadro 1.

Quadro 1 - Identificação e perfil dos participantes da pesquisa

\begin{tabular}{|l|l|l|l|l|}
\hline No & \multicolumn{1}{|c|}{ IDENTIFICAÇÃO } & \multicolumn{1}{|c|}{ FUNÇÃO } & $\begin{array}{l}\text { TEMPO DE } \\
\text { TRABALHO }\end{array}$ & $\begin{array}{l}\text { TEMPO NO } \\
\text { PROGRAMA }\end{array}$ \\
\hline 1 & $\begin{array}{l}\text { Coordenação } \\
\text { pedagógica E. E. } \\
\text { Ensino Médio 1 }\end{array}$ & $\begin{array}{l}\text { Professor/a articulador/a do Pro-EMI e } \\
\text { Coordenador/a Pedagógico/a do Programa } \\
\text { "Escola Cidadã Integral". }\end{array}$ & 18 anos & 1 ano \\
\hline 2 & $\begin{array}{l}\text { Coordenação } \\
\text { pedagógica E. E. } \\
\text { Ensino Médio 2 }\end{array}$ & $\begin{array}{l}\text { Professor/a articulador/a do Pro-EMI e } \\
\text { Coordenador/a Pedagógico/a do Programa } \\
\text { "Escola Cidadã Integral". }\end{array}$ & 1 ano \\
\hline
\end{tabular}




\begin{tabular}{|l|l|l|l|l|}
\hline 3 & $\begin{array}{l}\text { Coordenação 3a } \\
\text { GRE/PB }\end{array}$ & $\begin{array}{l}\text { Técnico/a administrativo/a do setor financeiro } \\
\text { da 3a GRE/PB. }\end{array}$ & - & 1 ano \\
\hline 4 & $\begin{array}{l}\text { Ex-Coordenação do } \\
\text { Pro-EMI/3a GRE/PB }\end{array}$ & $\begin{array}{l}\text { Ex-Coordenador/a Pedagógico/a do Pro-EMI } \\
\text { na 3 3a GRE/PB (C. Grande). }\end{array}$ & $\begin{array}{l}\text { Coordenou } \\
\text { o Pro-EMI de } \\
2013 \text { a } 2015\end{array}$ \\
\hline
\end{tabular}

Fonte: A autora, a partir das entrevistas ${ }^{3}$.

É importante ressaltar que esses profissionais são, para além de servidores públicos (agentes do Estado), interlocutores chaves, responsáveis pela gestão pedagógica dos programas educacionais, dentre os quais o Pro-EMI. Como toda pessoa/profissional, possui vontades, interesses, vinculações a outras instituições (sindicatos, partidos, ideologias, crenças e outras). Com relação à participante número 4, esclarecemos que ela atuou na coordenação do ProEMI na 3a GRE/PB no período de 2013 a 2015 e atualmente exerce função de coordenadora pedagógica em uma escola de Ensino Médio na referida cidade, que até 2016 atuou com o Programa, mas mudou para ensino técnico (parcial e integral) e integrado (acadêmico e técnico).

\section{Programa Ensino Médio Inovador (Pro-EMI) em Campina Grande/PB}

Nas políticas adotadas a partir de 2007, o Pro-EMI, surge com a pretensão de ampliar o tempo de escolarização para um mínimo de sete horas diárias, sendo entendido como educação integral. Na Paraíba, o Programa teve início em 2009, sendo efetivado em 2012 com a adesão de 27 escolas, ampliado para 48 em 2013 e para 49 em 2014. Analisando os investimentos no Programa no biênio 2012-2013, tem-se o Quadro 3.

Quadro 2 - Adesão e investimentos no Pro-EMI no biênio 2012-2013 (R\$)

\begin{tabular}{|c|c|c|c|c|c|c|}
\hline \multicolumn{4}{|c|}{ ATUAÇÃO } & \multicolumn{3}{|c|}{ INVESTIMENTO } \\
\hline Ano & Escolas & Municípios & Alunos & Alimentação & Gratificação & Transporte \\
\hline 2012 & 26 & 21 & 12.346 & $1.458 .976,00$ & 3.827.400,00 & $799.700,00$ \\
\hline 2013 & 48 & 38 & 17.238 & 2.867.418,00 & $5.919 .000,00$ & $603.000,00$ \\
\hline
\end{tabular}

Fonte: A autora, a partir de dados disponíveis em Paraíba (2014)

Como percebemos, o Pro-EMI cresceu para atender a jovens com idade entre quinze e dezessete anos em escolas do sistema regular, selecionadas dentre as que apresentavam as condições físicas e organizacionais mais apropriadas para permanência dos estudantes em dois turnos. De acordo com a Lei n 13.005/2014, que aprova o Plano Nacional de Educação (PNE), estabelece a meta 6, que é alcançar um percentual de $25 \%$ das matrículas da educação 
básica com educação em tempo integral de 2014. Em Campina Grande/PB, de 2013 a 2016 a educação integral apresentou o seguinte quadro de matrículas:

Quadro 3: Matrículas em tempo integral no munícipio de Campina Grande/PB (2013 - 2016)

\begin{tabular}{|l|l|l|l|l|l|l|}
\hline \multirow{3}{*}{ ANO } & \multicolumn{3}{|l|}{ ENSINO FUNDAMENTAL } & \multicolumn{2}{l|}{ ENSINO MÉDIO } \\
\cline { 2 - 6 } & \multicolumn{2}{|l|}{ ANOS INICIAIS } & \multicolumn{2}{l|}{ ANOS FINAIS } & \multicolumn{2}{l|}{} \\
\cline { 2 - 6 } & TOTAL & INTEGRAL & TOTAL & INTEGRAL & TOTAL & INTEGRAL \\
\hline $\mathbf{2 0 1 3}$ & 18.271 & $4.682(25,6 \%)$ & 19.175 & $3.982(20,7 \%)$ & 9.665 & $2.015(20,4 \%)$ \\
\hline $\mathbf{2 0 1 4}$ & 17.110 & $7.179(42 \%)$ & 17532 & $4.873(28 \%)$ & 9.332 & $1.952(20,9 \%)$ \\
\hline $\mathbf{2 0 1 5}$ & 16.632 & $7.037(42,3 \%)$ & 17836 & $1.974(11 \%)$ & 9305 & $1.995(21,4 \%)$ \\
\hline $\mathbf{2 0 1 6}$ & 16.455 & $4.362(26,5 \%)$ & 17.562 & $1.174(6,7 \%)$ & 10.189 & $1.663(16,3 \%)$ \\
\hline
\end{tabular}

Fonte: A autora, a partir de dados disponiveis em Brasil (2017b).

Nos anos iniciais do Ensino Fundamental, que atende a crianças com idade entre 6 e 10 anos, encontra-se um aumento significativo das matrículas na educação integral de 2013 para 2014, ano em que se reelegeu Dilma Roussef para presidente da república. Essa taxa se manteve quase inalterada em 2015, caindo bruscamente em 2016, devido ao corte nas verbas. No Ensino Médio, o percentual de redução foi menor porque não havia crescido significativamente no período.

Em Campina Grande/PB, o Pro-EMI foi implantado em 2012 em quatro escolas da rede estadual. Segundo os participantes da pesquisa, o Programa tem apresentado altas taxas de evasão e transferência de estudantes, alegando dificuldade para permanecer sete horas na escola e falta de tempo para estudar para o Exame Nacional do Ensino Médio (ENEM), dentre outros. Também apresenta transferência de professores, alegando que a gratificação de $\mathrm{R} \$$ 600,00 a mais nos salários para dedicação exclusiva à escola não compensa os salários obtidos em outras escolas. Outro problema é a implementação dos macrocampos, que são campos disciplinares oferecidos no contraturno das disciplinas "tradicionais".

Em 2017 a adesão ao Programa em Campina Grande/PB apresenta-se da seguinte forma:

Quadro 4 - Mudanças na adesão das escolas ao Pro-EMI

\begin{tabular}{|l|l|l|l|l|l|l|l|}
\hline NO$^{\mathbf{E}}$ & ESCOLAS & $\mathbf{2 0 1 2}$ & $\mathbf{2 0 1 3}$ & $\mathbf{2 0 1 4}$ & $\mathbf{2 0 1 5}$ & $\mathbf{2 0 1 6}$ & $\mathbf{2 0 1 7}$ \\
\hline 1 & EEEFM Severino Cabral & Sim & $\operatorname{Sim}$ & $\operatorname{Sim}$ & $\operatorname{Sim}$ & $\operatorname{Sim}$ & Não \\
\hline 2 & EEEFM Isabel Rodrigues de melo & Não & $\operatorname{Sim}$ & $\operatorname{Sim}$ & $\operatorname{Sim}$ & $\operatorname{Sim}$ & Não \\
\hline 3 & EEEFM Dr. Hortêncio de S. Ribeiro & Sim & $\operatorname{Sim}$ & $\operatorname{Sim}$ & $\operatorname{Sim}$ & Não & Não \\
\hline 4 & EEEFM Dr. Elpídio de Almeida & $\operatorname{Sim}$ & $\operatorname{Sim}$ & $\operatorname{Sim}$ & $\operatorname{Sim}$ & $\operatorname{Sim}$ & Não \\
\hline 5 & EEEFM Raul Córdola & Não & Não & Não & Não & Não & Sim \\
\hline 6 & EEEFM Monte Carmelo & Não & Não & Não & Não & Não & Sim \\
\hline 7 & EEEFM João Lelys & Não & Não & Não & Não & Não & Sim \\
\hline
\end{tabular}

Fonte: A autora, a partir de dados disponibilizados pela Coordenação do PDDE na $3^{a} G R E / P B$

As quatro escolas que haviam aderido ao Programa foram desvinculadas, dentre as quais duas que estavam sendo pesquisadas. Essas aderiram a um programa criado em 2016 
pelo governo do Estado, Ricardo Coutinho, denominado "Escola Cidadã Integral", cuja gestão tem sido assessorada pelo Instituto de Corresponsabilidade pela Educação (ICE), que é uma empresa privada sem fins lucrativos. O Programa é inspirado no que vem sendo adotado em Pernambuco desde 2004.

Em 2015, mesmo antes da substituição do Pro-EMI, as escolas ficaram sem receber os aportes financeiros do Governo Federal, devido à conjuntura (crise) político-econômica iniciada naquele ano. Segundo os entrevistados, as escolas desenvolveram suas atividades com saldo em conta do ano anterior, acrescido dos recursos do convênio de alimentação escolar para o almoço dos estudantes. Em Campina Grande/PB, de 2013 a 2017, o número de matrículas evoluiu da seguinte forma:

Quadro 5 - Número de escolas cadastradas no Pro-EMI e de alunos matriculados

\begin{tabular}{|l|l|l|l|}
\hline Pro-EMI & $\mathbf{2 0 1 3}$ & $\mathbf{2 0 1 5}$ & $\mathbf{2 0 1 7}$ \\
\hline Escolas cadastradas & 4 & 4 & 3 \\
\hline Número de matrículas & 2.679 & 2.388 & 3.063 \\
\hline
\end{tabular}

Fonte: A autora, a partir de dados disponibilizados pelo Coordenador do PDDE na $3^{a} G R E / P B$

Nas duas escolas de Ensino Médio pesquisadas houve uma pequena oscilação nas matrículas a menor, conforme o Quadro 6.

Quadro 6 - Evolução das matrículas nas escolas pesquisadas

\begin{tabular}{|l|l|l|l|l|l|}
\hline ANO & $\mathbf{2 0 1 1}$ & $\mathbf{2 0 1 2}$ & $\mathbf{2 0 1 3}$ & $\mathbf{2 0 1 4}$ & $\mathbf{2 0 1 5}$ \\
\hline E. E. Ensino Médio 1 & 423 & 334 & 186 & 272 & 261 \\
\hline $1^{\circ}$ & 364 & 295 & 202 & 167 & 217 \\
\hline $2^{\circ}$ & 245 & 266 & 189 & 164 & 141 \\
\hline $3^{\circ}$ & 1.032 & 895 & 577 & 603 & 619 \\
\hline TOTAL & \multicolumn{5}{|l|}{} \\
\hline E. E. Ensino Médio 2 & 224 & 283 & 194 & 104 & 156 \\
\hline $1^{\circ}$ & 184 & 188 & 153 & 116 & 105 \\
\hline $2^{\circ}$ & 126 & 158 & 132 & 104 & 115 \\
\hline $3^{\circ}$ & 534 & 629 & 479 & 324 & 376 \\
\hline TOTAL &
\end{tabular}

Fonte: A autora, a partir de dados disponíveis em Qedu (2017).

Segundo os professores, os alunos alegavam a necessidade de estudar em cursinho pré-Exame Nacional de Ensino Médio (ENEM), trabalho e/ou falta de adaptação à dinâmica de trabalho adotada com o Pro-EMI (SALVINO e ROCHA, 2014). Essa informação possibilita inferir que a imprecisão, associada à função do Ensino Médio (acadêmico, propedêutico ou profissional), persiste. A Lei n 9.394/1996, Lei de Diretrizes e Bases da Educação Nacional (LDB), no seu Art. 35, procurou resolver essa imprecisão, estabelecendo as finalidades seguintes, 
I - A consolidação e o aprofundamento dos conhecimentos adquiridos no ensino fundamental, possibilitando o prosseguimento de estudos;

II - a preparação básica para o trabalho e a cidadania do educando, para continuar aprendendo, de modo a ser capaz de se adaptar com flexibilidade a novas condições de ocupação ou aperfeiçoamento posteriores;

III - o aprimoramento do educando como pessoa humana, incluindo a formação ética e o desenvolvimento da autonomia intelectual e do pensamento crítico;

IV - a compreensão dos fundamentos científico-tecnológicos dos processos produtivos, relacionando a teoria com a prática, no ensino de cada disciplina. (BRASIL, 1996, p. 12).

Como percebemos, as finalidades são amplas e abarcam as dimensões da continuidade dos estudos; formação profissional; formação humana e científica, inclusive retirando a equivalência entre ensino regular e profissional. Porém as políticas adotadas a partir de 2010 foram gradativamente retomando e corroborando o ensino técnico-profissional, o que se reflete na ampliação dos Institutos Federais de Educação e do PRONATEC ${ }^{4}$. Recentemente, a Lei $n^{\circ}$ 13.415/2017 (BRASIL, 2017) alterou a LDB/1996, flexibilizando ainda mais a oferta de Ensino Médio. Dentre outras coisas, estabeleceu que os últimos períodos fossem compostos por "itinerários formativos, que deverão ser organizados por meio da oferta de diferentes arranjos curriculares" (BRASIL, 2017, p. 13) a serem escolhidos pelos estudantes, mediante a oferta de áreas, a saber: 1) Linguagens e suas tecnologias; 2) Matemática e suas tecnologias; 3 ) Ciências da Natureza e suas tecnologias; 4) Ciências Humanas e suas tecnologias; 5) Formação Técnica e Profissional. Ou seja, ampliou mais uma vez a dimensão técnica da educação básica, embora em outros artigos a LDB/1996 estabeleça também normas para a educação integral.

\section{RESSIGNIFICANDO O CURRÍCULO E REDEFININDO POSIÇÕES}

Em âmbito nacional, o Pro-EMI foi reconstituído em 2016, passando a ser nominado de Novo Programa Ensino Médio Inovador (Novo Pro-EMI). Para uma melhor compreensão dessa reconstituição, o Quadro 7 apresenta um comparativo entre os dois projetos.

Quadro 7 - Comparativo entre o Pro-EMI e o Novo Pro-EMI

\begin{tabular}{|l|l|l|}
\hline$N^{\circ}$ & PRO-EMI & NOVO PRO-EMI \\
\hline 1 & $\begin{array}{l}\text { Redesenho curricular para o Ensino Médio, } \\
\text { disseminando a cultura para o desenvolvimento de } \\
\text { interface entre os conhecimentos das diferentes } \\
\text { áreas e a realidade dos estudantes, atendendo suas } \\
\text { necessidades e expectativas. }\end{array}$ & $\begin{array}{l}\text { Os conhecimentos e sua produção deverão } \\
\text { dialogar com o projeto de vida dos estudantes } \\
\text { na diversidade de contextos. Articulação entre } \\
\text { conhecimentos, o que pressupõe currículo } \\
\text { flexível, a partir de quatro áreas (Linguagens, } \\
\text { Matemática, Ciências Humanas e Ciências da } \\
\text { Natureza). }\end{array}$ \\
\hline 2 & $\begin{array}{l}\text { Considera como despesas de Capital equipamentos } \\
\text { e mobiliários; de custeio, a aquisição de materiais, } \\
\text { serviços e locações, observando as categorias e } \\
\text { especificações da Portaria do STN/MF n 448/ 2002. }\end{array}$ & Mantido igual. \\
\hline
\end{tabular}




\begin{tabular}{|c|c|c|}
\hline 3 & $\begin{array}{l}\text { Macrocampos articulados às } 4 \text { áreas de } \\
\text { conhecimento e às disciplinas "tradicionais" }\end{array}$ & $\begin{array}{l}\text { Campos de Integração Curricular (CIC) } \\
\text { articulados às } 5 \text { áreas de conhecimento } \\
\text { propostas pela MP nº } 476 / 2016\end{array}$ \\
\hline 4 & $\begin{array}{l}\text { Macrocampos: 1) Acompanhamento Pedagógico } \\
\text { (Linguagens, Matemática, Ciências Humanas e } \\
\text { Ciências da Natureza)*; 2) Iniciação Científica e } \\
\text { Pesquisa*; 3) Leitura e Letramento*; 4) Línguas } \\
\text { Estrangeiras; 5) Cultura Corporal; 6) Produção e } \\
\text { Fruição das Artes; 7) Comunicação, Cultura Digital } \\
\text { e uso de Mídias; 8) Participação Estudantil. }\end{array}$ & $\begin{array}{l}\text { Campos de Integração Curricular (CIC): 1) } \\
\text { Acompanhamento Pedagógico (Port./Mat.)*; 2) } \\
\text { Iniciação Científica e Pesquisa*; 3) Mundo do } \\
\text { Trabalho*; 4) Línguas Adicionais/Estrangeiras*; } \\
\text { 5) Cultura Corporal; 6) Produção e Fruição das } \\
\text { Artes; 7) Comunicação, Uso de Mídias e Cultura } \\
\text { Digital; 8) Protagonismo Juvenil. }\end{array}$ \\
\hline 5 & $\begin{array}{l}\text { A escola deverá contemplar os três macrocampos } \\
\text { obrigatórios* e pelo menos mais dois a sua } \\
\text { escolha, totalizando } 5 \text {, no mínimo. }\end{array}$ & $\begin{array}{l}\text { A escola deverá contemplar } 4 \text { CIC obrigatórios } \\
\text { e pelo menos mais } 01 \text { (um) CIC de sua } \\
\text { escolha, totalizando 5, no mínimo. }\end{array}$ \\
\hline 6 & $\begin{array}{l}\text { O macrocampo "Acompanhamento Pedagógico" } \\
\text { deverá fortalecer os componentes curriculares, } \\
\text { tendo como referência os objetivos constantes } \\
\text { no PPP da escola. As atividades poderão } \\
\text { contemplar um ou mais componentes, objetivando } \\
\text { aprofundar conhecimentos específicos por meio } \\
\text { de planejamento flexível, com conteúdos e } \\
\text { metodologias diferenciadas. }\end{array}$ & $\begin{array}{l}\text { O CIC "Acompanhamento Pedagógico" deverá } \\
\text { fortalecer os componentes curriculares, tendo } \\
\text { como referência Port./Mat. e objetivos do PPP } \\
\text { da escola. As atividades deverão aprofundar } \\
\text { conhecimentos da língua portuguesa e da } \\
\text { matemática, por meio de planejamento } \\
\text { flexível, estabelecendo conteúdos e } \\
\text { metodologias diferenciados. }\end{array}$ \\
\hline 8 & $\begin{array}{l}\text { Composição de comitê gestor em cada secretaria, } \\
\text { com Coordenador de Ensino Médio da Secretaria } \\
\text { de Educação; } 2 \text { membros da Equipe Técnico- } \\
\text { Pedagógica da Coord. de E. M. do respectivo } \\
\text { sistema de ensino; • Membro da Área Financeira da } \\
\text { Secretaria Estadual/Distrital. }\end{array}$ & $\begin{array}{l}\text { Composição de Comitê Gestor em cada } \\
\text { secretaria, com Coordenador de Ensino Médio } \\
\text { da Secretaria de Educação; } 2 \text { (dois) Membros } \\
\text { da Equipe Técnico-Pedagógica da Coord. de } \\
\text { E. M. do respectivo sistema; Membro da Área } \\
\text { Financeira da Secretaria Estadual/Distrital. }\end{array}$ \\
\hline 9 & $\begin{array}{l}\text { Às escolas que tenham seus PRC aprovados serão } \\
\text { destinados, por meio de suas Unidades Executoras } \\
\text { (UEX) próprias, recursos de custeio e de capital, } \\
\text { tomando os intervalos de classe de número de } \\
\text { alunos matriculados no Ensino Médio da unidade } \\
\text { educacional extraído do censo escolar do ano } \\
\text { anterior ao do repasse, a carga horária escolar e } \\
\text { os correspondentes valores de referência, seja de } \\
5 \text { horas/dia (Tabela 1), oferta do Ensino Médio } \\
\text { Noturno (Tabela 1) ou de Tempo Integral de } 7 \\
\text { horas/dia já instituída. }\end{array}$ & $\begin{array}{l}\text { Às escolas que tiverem seus PRC aprovados, serão } \\
\text { destinados, por meio das Unidades Executoras } \\
\text { (UEX) próprias, recursos de custeio e de capital, } \\
\text { tomando os intervalos de classe de número de } \\
\text { alunos matriculados no ensino médio da unidade } \\
\text { educacional extraído do censo escolar do ano } \\
\text { anterior ao do repasse, a carga horária escolar e } \\
\text { os correspondentes valores de referência, seja de } \\
5 \text { horas/dia (Tabela 1), oferta do Ensino Médio } \\
\text { Noturno (Tabela 1) ou de Tempo Integral de } 7 \\
\text { horas/dia já instituída. }\end{array}$ \\
\hline
\end{tabular}

Fonte: A autora, a partir de dados disponiveis em Brasil (2014; 2016)

Constata-se que o Novo Pro-EMI apresenta poucas alterações quando comparado ao Pro-EMI. As principais mudanças foram: mudança da nomenclatura de "macrocampos" 
para "campos de integração"; ênfase ao Campo de Integração Curricular, denominado "Acompanhamento Pedagógico", dando-lhe a função de reforço em Língua Portuguesa e Matemática; acréscimo do Campo de integração "Mundo do Trabalho". No Novo Pro-EMI, as escolas são divididas em grupos para efeito de distribuição de recursos: G1: escolas que receberam recursos do Programa em 2014; G2: escolas com Nível Socioeconômico baixo ou muito baixo segundo INEP, que não se enquadrem no critério do G1; G3: demais escolas de EM que poderão aderir ao Programa.

Ao aderir ao Pro-EMI, as escolas se comprometiam a realizar um Projeto de Redesenho Curricular (BRASIL, 2009) e, para isto, alguns professores das escolas pesquisadas, em 2012, viajaram ao Rio de Janeiro para cursos preparatórios e visitas a escolas tidas como inovadoras. Além disso, o MEC desenvolveu um programa de formação continuada nas próprias escolas, coordenado por professores das instituições que participavam de treinamento em João Pessoa (capital do Estado). O esforço foi no sentido de implementar os "macrocampos", considerando que eles deveriam tornar o currículo mais atrativo e inovador.

No primeiro ano dessa formação houve uma série de denúncias contra a gestora (eleita) da E. E. Ensino Médio 1, que foi afastada do cargo pelo governo do Estado, nomeando interinamente o professor que coordenava a formação continuada em final de 2014. 0 fato gerou divergências e conflitos internos. O professor foi eleito em 2015, quando as desavenças cessaram, mas se intensificaram com a desvinculação da escola do Pro-EMI e adesão ao "Programa Escola Cidadã Integral". Sobre essa adesão uma das entrevistadas, afirma:

Apenas recebemos a notícia de que não haveria mais o Pro-EMI e que a escola faria adesão ao
"Programa Escola Cidadã Integral" do governo estadual. São as políticas públicas, as escolhas
da Secretaria da Educação. Com a mudança, professores da instituição, que já trabalhavam
aqui há vários anos tiveram que se submeter a uma seleção, mesmo sendo concursados,
para poder lecionar no novo programa. Foi uma confusão, houve muitos problemas.
Chegaram a dizer que eu apenas olhava para o meu umbigo. Fiquei preocupada, mas me
dei conta que precisava continuar trabalhando na escola e que muitas das conversas tinham
o intuito de afetar o atual gestor. Então, resolvi continuar na escola. Mas, sei que o corte
de verbas influenciou para o fim do Pro-EMI (COORDENAÇÃO E. ENSINO MÉDIO 1, 2017).

As discórdias, segundo a participante, tiveram como motivação os seguintes fatos: os professores desejavam que a escola não fizesse a adesão e entendiam que o gestor poderia impedir isto; houve uma seleção interna para os professores permanecerem na escola e quem não foi aprovado teve quer sair; o Programa exige dedicação exclusiva, garantindo uma gratificação no valor de $\mathrm{R} \$ 1.000,00$ e eles afirmavam que esse valor não cobria os salários recebidos em outras instituições; os professores exigiam que a entrevistada se posicionasse favorável às suas reivindicações.

Em consequência, um número de professores foi transferido da escola, por opção ou não aprovação na seleção. No dia da entrevista (10/04/2017), várias disciplinas estavam sem professores e os que estavam na escola eram prestadores de serviços temporários. Apenas três professores da época do Pro-EMI permaneciam na escola e o Programa Escola Cidadã Integral já havia sido instituído legalmente desde fevereiro de 2016. Portanto, todo o trabalho empreendido em quatro anos do Pro-EMI havia sido desmontado e o novo programa enfrentava sérias dificuldades para se estabelecer. 
A E. E, Ensino Médio 2 optou por outra trajetória, mas enfrentou problemas internos também graves. Como o Pro-EMI estabelecia autonomia para as escolas decidirem sobre o redesenho curricular, a equipe da escola decidiu inspirar-se no "Projeto da Escola da Ponte" de Portugal, chegando a manter contato com um dos seus idealizadores, o educador José Pacheco, que os orientou em diversas ocasiões. O entrevistado da E. E Ensino Médio 2 (2017) informou que chegou a viajar a Brasília para participar de eventos sobre o tema. Segundo ele, os principais esforços foram no sentido de organizar as atividades em núcleos, em vez de séries; adotar a metodologia de projetos, conforme interesse dos estudantes, nos quais os professores atuariam como tutores; modificar o sistema de avaliação, abolindo as notas. Ao ser interrogado por que o Programa havia sido interrompido, obtivemos a seguinte resposta:

\begin{abstract}
Houve interrupção também por conta do corte de verbas em 2015, mas principalmente por questões internas. E isso deu uma dor de cabeça grande. Tínhamos alguns projetos caros e estávamos apostando... [...]. Uma das coisas que queríamos era lutar pela autonomia da escola e também política. Chegamos a fazer contato, com as verbas do Pro-EMI para criar um diário eletrônico e poder substituir o sistema de caderneta (impresso). Estávamos desenvolvendo um sistema unificado, inspirados no projeto da "Escola da Ponte". Não teríamos alunos de primeiro, segundo e terceiro ano... seriam todos alunos do Ensino Médio. Sairiam da escola quando realmente tivessem aprendido. Sem haver reprovação. A escola é o único meio de aprendizagem que se afasta radicalmente de como a natureza nos faz aprender [...]. A escola é viva e vai se transformando. Eles aprendem a agir na democracia, sabem que tem poder para mudar as coisas. Havia na escola um grupo que queria o projeto, outro que se deixava levar e outro que não queria de jeito nenhum. Enquanto a gente era sempre lutando para ancorar e fazer o projeto crescer, tinha sempre quem puxasse para baixo, inclusive a secretaria que sempre ligava para reclamar e lembrar que estávamos agindo sem que a legislação permitisse. O Pro-EMI objetivava a inovação e, para isto, a escola tinha autonomia. Se o grupo que era contra tivesse outro projeto, seria bom, mas não tinham. Sai da escola em 2015 e aí desandou de vez. Voltei em 2016, através da seleção, por causa do Escola Cidadã Integral porque uns colegas ligaram dizendo que o projeto atual tem muito do que pretendíamos fazer com o Pro-EMI. O corte de verba não foi tão importante. Vou parafrasear Pacheco: "As escolas não são prédios, as escolas são pessoas". A verba é importante, mas... Não tínhamos as condições necessárias porque na época [...], tínhamos planos para a verba daquele ano que não veio... a verba de 2014 veio chegar em2016 (COORDENAÇÃO E. ENSINO MÉDIO 2, 2017).
\end{abstract}

Segundo o entrevistado, a burocracia da $3^{\circ}$ GRE/PB também contribuiu para o fracasso do projeto, principalmente por não concordar com a avaliação, com a não seriação e com a não disciplinarização. Também porque os professores se dividiram em três grupos, a saber: professores que, como ele, acreditavam no projeto e agiam para o seu êxito; professores que acreditavam menos, mas que colaboravam; professores contrários, que agiam para o fracasso. A escola deixou o Pro-EMI em janeiro de 2017, também aderindo ao Programa Escola Cidadã Integral.

Mediante os relatos, os motivos para a descontinuidade do Pro-EMI não estiveram decisivamente ligados à conjuntura nacional (impeachment, recessão, corte de verbas, etc.), mas aos problemas internos. Os relatos confirmam, a nosso ver, as escolas como microespaços de políticas e de relações de poder, nos quais o currículo se situa como campo de disputa pela legitimação do que deve ser ensinado/aprendido. Como o poder não é uma relação apenas hierárquica, a (des)continuidade, portanto, não decorre apenas das ações das elites políticas/ governantes, mas dos próprios grupos nos processos de recontextualização das políticas, ou seja, nos contextos de prática, como analisa Mainardes (2006).

Com relação aos aspectos que foram continuados, conforme a percepção do/a entrevistado/a, destacamos os relatos do Quadro 8. 
Quadro 8 - Aspectos do Pro-EMI que têm sido continuados

Coordenação da E. E. Ensino Médio 1

Houve aspectos que continuaram, "Minha atuação hoje é pelo que vivenciei no PRO-EMI, como a carga horária, assim como as formações. Ser docente é sempre aprender". O PRO-EMI funcionava com a base comum (disciplinas) no turno da manhã e à tarde com os macrocampos. Desta forma, a escola à tarde encontrava-se praticamente vazia. Agora no Cidadã Integral estes componentes são misturados, fazendo com que os alunos permaneçam na instituição. O Programa Cidadã Integral é dividido com $10 \mathrm{~h}$ aula e uma professora articuladora. Sendo que a coordenação de área, tem que dedicar-se $8 \mathrm{~h}$ aula. Houve redução de alunos nos primeiros anos com o PRO-EMI. O Escola Cidadã Integral é Programa do governo estadual, assessorado pelo Instituto de Corresponsabilidade pela Educação (ICE), que é uma empresa privada paga para isto e tem por trás a Natura e o Banco Itaú. O ICE desenvolve um projeto que considero bom, mas que a escola não tem autonomia. Tudo é muito planejado e controlado. Muitos dos professores saíram da escola e 2017 está começando com a maioria de professores que trabalham em regime temporário. A maioria chegou na escola 4 dias antes do início das aulas e não participou da formação como os demais.

Coordenação da E. E. Ensino Médio 2

Do projeto desenvolvido a partir do Pro-EMI, alguns mecanismos continuaram. O parlamento juvenil foi praticamente ressuscitado, funcionou sozinho o primeiro semestre do ano passado (2016). Esse é um projeto educativo e de formação política dos alunos, é uma agremiação estudantil, sendo incluso no Projeto da escola. A tutoria é outra atividade que continua, que tínhamos a presença dos pais nas reuniões com os tutores. E outra é a prática do diagnóstico para definir o que se deve trabalhar a partir dele. Com o parlamento juvenil, com um grupo de 15 alunos (mais ou menos), representantes de 11 turmas. Tem servido para que eles consigam realizar suas coisas sem precisar de adultos. Nesse projeto agora tem o "projeto de vida", que pretende fazer eles se libertarem da presença, sempre, do professor. Vieram muitas coisas boas nesse novo projeto, mas veio consigo a perda de autonomia que se pretendia com o Pro-EMI. O Instituto Corresponsabilidade pela Educação (ICE), de onde vem os formadores, financiados pelo "Sonho Grande", que por sua vez são financiados pela Natura e Itaú, vem e conversam com os alunos do Parlamento para saber se há o cumprimento das regras que são pedidas pelo projeto. Ex-Coordenação do Pro-EMI/3a GRE/PB

Além do investimento do ensino em tempo integral, outro aspecto relevante foi uma renovação nos "antigos" macrocampos que foram subdivididos em disciplinas eletivas e atividades de complementação curricular.

Fonte: A autora, a partir dos questionários e das entrevistas.

Os participantes abordam novamente a relação público-privado, demonstrando que os fundamentos inerentes ao Pro-EMI são mais condizentes com os pressupostos da educação integral, dentre os quais o da autonomia das escolas para decidirem sobre seus projetos pedagógicos. No programa Escola Cidadã Integral essa autonomia é reduzida, uma vez que o ICE presta assessoria com base na Tecnologia de Gestão da Educação (TGE), tendo como dos seus parceiros o STEM - Brasil, um braço da World Fund for Education, uma instituição norte-americana com atuação expandida para a América Latina ${ }^{5}$ (ICE, 2018). Esta instituição é adepta e vinculada à rede de Escola Charter, da qual emerge o projeto da Escola da Escolha, que fundamenta o ICE. O ICE tem como parceiros financiadores o Instituto Natura, o Instituto 
Sonho Grande, o Instituto Espírito Santo em Ação, a Fundação Itaú Social, a FIAT, a JEEP e outros. Essas empresas firmam contratos com as secretarias de educação em troca de isenções e imunidades fiscais. Trata-se, portanto, de uma complexa rede de políticas, de uma parceria público-privada, que representa na privatização da gestão das escolas. Nesse sentido, esse modelo de gestão é mais condizente com a lógica de mercado. Como sinaliza Ball,

Dessa forma, a perspectiva de negócios é exercida sobre questões e problemas sociais e
educacionais. Isso é indicativo de uma mudança genérica dentro da filantropia empresarial
em direção a formas de filantropia estratégica e de desenvolvimento, com base nos métodos
de investimento de capital privado, uma mistura especial de cuidado e cálculo, ou como
Bronfman e Solomon (2009) colocam no subtítulo de seu livro The Art of giving (A arte de
doar), esse é o lugar onde: 'a alma encontra um plano de negócios' (BALL, 2014, p. 122).

O ICE foi criado em 2004 em Pernambuco, mas em 2017 já havia se expandido para escolas de 17 estados do Brasil. Nesse período, o Índice Desenvolvimento da Educação (EDEB) de Pernambuco saiu da $22^{a}$ para a $1^{a}$ colocação. Os relatos são de que com a TGE as escolas realizam planejamento sistemático e rigoroso, enfatizando o protagonismo estudantil, enquanto os profissionais, as escolas e os currículos são submetidos a formas de controle e regulação mais rigorosos e efetivos, inclusive com fichas de avaliação, exercidos pelas próprias pessoas das comunidades escolares, tais como estudantes, coordenadores, gestores e parentes dos estudantes. É prematuro inferir sobre efeitos e resultados com relação ao desempenho dos estudantes e das escolas por meio da TGE. Mas uma coisa é certa, as escolas referidas e suas equipes perderam a oportunidade de desenvolver projetos com determinado nível de autonomia por meio do Pro-EMI.

\section{CONSIDERAÇÕES FINAIS}

No Ensino Médio há vários aspectos que merecem destaque, a saber: há vários modelos de organização curricular 6 , às vezes, mais de um adotado numa mesma escola; a reforma regulamentada pela Lei no 13.415/2017, estabelecendo que todas as escolas deverão adotar o regime de tempo integral; a Base Nacional Comum Curricular (BNCC) em tramitação no Conselho Nacional de Educação (CNE), a partir da qual os currículos das escolas deverão ser reorganizados.

Há uma série de imprecisões, incertezas, problemas difíceis de serem minimizados e/ou resolvidos. O fato é que, de 2007 ao início de 2015, toda uma sinergia foi canalizada em função do desenvolvimento do Pro-EMI, inclusive durante o primeiro mandato da ex-presidente Dilma Rousseff (2010-2014). Porém, a crise política, que culminou com o impeachment da exPresidente, com o seu afastamento e a posse de Michel Miguel Temer como presidente do Brasil e de José Mendonça Bezerra Filho para Ministro da Educação, marcou a reconstituição do Programa. Os novos direcionamentos associam-se a uma retomada de concepções mais conservadoras de educação, como a ênfase em determinadas disciplinas em detrimento de outras quando deveria aperfeiçoar a integração curricular. Também quando avança no projeto iniciado com o "Movimento Compromisso todos pela Educação", cuja proposta de pactuação tem favorecido a parceria público-privado que, no caso das escolas pesquisadas, tem se dado entre o Estado e o ICE, que é uma empresa declarada como filantrópica e que gradativamente amplia seu ângulo de atuação, já assessorando redes de ensino em vários Estados brasileiros. 
As continuidades e as descontinuidades evidenciadas nas duas escolas situam-se no complexo processo de reordenação do capitalismo e do neoliberalismo roll-out que, favorecido pelo avanço das tecnologias de informação e comunicação, intensificando as parcerias público-privadas e a governança em redes, que dão novos sentidos à gestão da educação e do currículo, bem como às relações (globais/locais), às disputas e aos mecanismos de regulação em torno do currículo de educação integral. Contudo, as escolas não são apenas reprodutoras de determinações neoliberais, mas espaço de política cultural, de modo que também produzem sentidos e significados culturais no processo de recontextualização e implementação das políticas neoliberais.

\section{REFERÊNCIAS}

BALL, S. Educação global S. A.: novas redes políticas e o imaginário neoliberal. Tradução de Janete Bridon. Ponta Grossa, PR: Editora da UEPG, 2014.

BALL, S. Performatividade, privatização e o Pós-estado do Bem-Estar. Educação e Sociedade, v. 25, n. 89, p. 1105-1126, Set./Dez. 2004.

BRASIL. Ministério da Educação. Lei no 9.394, de 20 de dezembro de 1996. Estabelece diretrizes e bases para a educação nacional. Brasília: MEC, 1996.

BRASIL. Ministério de Educação. Programa Ensino Médio Inovador: documento orientador. Brasília: MEC, 2014.

BRASIL. Ministério da Educação. Portaria n 971, de 9 de outubro de 2009. Brasília: MEC, 2009.

BRASIL. Ministério da Educação. Portaria n 1.144, de 10 de outubro de 2016. Brasília: MEC, 2016.

BRASIL. Ministério da Educação. Lei n 1.3415, de 16 de fevereiro de 2017. Altera as Leis $\mathbf{n}^{\circ}$ 9.394, de 20 de dezembro de 1996, que estabelece as diretrizes e bases da educação nacional, e 11.494, de 20 de junho 2007. Brasília: MEC, 2017.

BRASIL. Instituto Nacional de Pesquisas Educacionais Anísio Teixeira. Educação Básica -IDEB. 2017b. Disponível em: http://portal.inep.gov.br/ideb . Acesso em 20 ago 2017.

CORAZZA, S. Planejamento de ensino como estratégia de política cultural. In: MOREIRA, A. F. (Org.). Currículo: questões atuais. Campinas, SP: Papirus, 1997.

CROSO, C.; MAGALHÃES, G. Privatização da educação na América Latina e no Caribe: tendências e riscos para os sistema públicos de ensino. In: Educação e Sociedade, Campinas, v. 37, nº. 134, p.17-33, jan.-mar., 2016. Disponível em: http://www.scielo.br/pdf/es/v37n134/1678-4626-es-37-134-00017. pdf. Acesso em: 20 dez. 2017.

COUTO, M. Mulheres de Cinza. As areia do imperador. Vol. 1. São Paulo: Companhia das Letras, 2015.

EL PAÍS. Após morte em escola ocupada de Curitiba, governador pressiona pelo fim do protesto. Disponível em: https://brasil.elpais.com/brasil/2016/10/25/politica/1477412784_340839.html. Acesso em out. 2017.

FREIRE, P. Pedagogia da autonomia. São Paulo: Paz e Terra, 1996. 
FREIRE, P. Pedagogia da indignação. São Paulo: Paz e Terra, 2002.

GIROUX, H. A. Descentralizando o Cânone: Retraçando as Fronteiras Disciplinares e Pedagógicas. Cruzando as fronteiras do discurso educacional: novas políticas em educação. Porto Alegre: Artes Médicas, 2002.

INSTITUTO DE CORRESPONSABILIDADE PELA EDUCAÇÃO - ICE. Escola da Escolha. Disponível em: http://icebrasil.org.br/escola-da-escolha/. Acesso em: 18 mar. 2018.

LACLAU, E.; MOUFF, C. Hegemonia e estratégia socialista. Traduzido por Joanildo Burity, Josias de Paula Jr. E Aécio Amaral. São Paulo: Intermeios; Brasília: CNPq, 2015.

LIMA JÚNIOR, A. S. de; ALMEIDA, D. F. Governança e TIC: uma outra perspectiva e seus desafios para a gestão pública. In: LIMA JÚNIOR, A. S. de; ANDRADE, D. M. M. (Orgs.). Educação e contemporaneidade: contextos e singularidades. Curitiba,PR: Editora CRV, 2015.

LOPES, A. C.; MACEDO, E. Teorias de currículo. São Paulo: Cortez, 2011.

Contribuições de Stephen Ball para o estudo de políticas de currículo. In: BALL, Stephen; MAINARDES, J. (Orgs.). Políticas Educacionais. São Paulo: Cortez, 2011.

MAINARDES, J. A abordagem do ciclo de políticas e suas contribuições para a análise da trajetória de políticas educacionais. Educação e Sociedade, Campinas, vol. 27, n. 94, p. 47-69, jan./abr.

PARAÍBA. Secretaria de Estado da Educação. Diretrizes operacionais para o funcionamento das escolas da rede estadual de ensino. João Pessoa, PB: SEE, 2014.

QEDU. Matrícula na educação básica. Disponível em: http://www.qedu.org.br/ Acesso: 30 out. 2017

SALVINO, F. P.; ROCHA, V. G. Macrocampos como proposta de integração e inovação curricular no programa ensino médio inovador. Revista e-Curriculum, São Paulo, v. 12, n. 03 p. 2019 - 2042 out./ dez. 2014.

SAVIANI, D. Política educacional brasileira: limites e perspectivas. Revista de Educação, PUCCampinas/SP, n. 24, p. 7-16, Jun. 2008.

SHIROMA, E. O.; GARCIA R.; CAMPOS, R. Conversão das "almas" pela liturgia da palavra: uma análise do discurso do movimento Todos pela Educação. In: BALL, S.; MAINARDES, J. (Orgs.). Políticas educacionais. São Paulo: Cortez, 2011.

TEIXEIRA, A. S. Pequena introdução à Filosofia da Educação: a escola progressiva ou a transformação da escola. 5. ed. São Paulo: Editora Nacional, 1967.

TOKARNIA, M. Sob o lema "Pátria Educadora", educação teve cortes no orçamento e greves em 2015. EBC Agência Brasil: Educação. 2015. Disponível em: http://agenciabrasil.ebc.com.br/educacao/ noticia/2015-12/sob-o-lema-patria-educadora-educacao-tem-cortes-no-orcamento-e-greves. Acesso em: 19 ago. 2017.

Artigo recebido em: 10/10/2017

Aprovado em: $12 / 04 / 2018$

Contato para correspondência:

Francisca Pereira Salvino.

E-mail: fpsalvino2@hotmail.com 
1 No ano de 2016, pela primeira vez desde 1996, todos os setores da economia recuaram: agropecuária $(-6,6 \%)$, indústria $(-3,8 \%)$ e serviços $(-2,7 \%)$. Segundo a Revista Época (2017), o que mais chamou a atenção dos analistas foi o recuo acentuado de dois dos principais motores do crescimento, o investimento e o consumo das famílias. A chamada Formação Bruta de Capital Fixo (FBCF), indicador de crescimento sólido, recuou pelo terceiro ano seguido, afetado pela queda da produção interna e da importação de bens de capital, como máquinas e equipamentos. A taxa de investimento do país recuou para $16,4 \%$, abaixo do nível de 2015 (18,1\%), sendo o menor número da série histórica do IBGE, que começou em 1996.

2 Mais de mil escolas chegaram a ser ocupadas no país. Em alguns estados, governadores autorizaram cortes de energia e água e proibiram entrada de alimentos. Houve acirrados conflitos entre ocupantes e não ocupantes que reivindicavam o direito de estudar e na escola Estadual Santa Felicidade, em Curitiba, o aluno Lucas Eduardo Araújo Mota, 16 anos, foi assassinado no dia 24/10/2016 dentro do colégio, por um colega após ingerirem drogas sintéticas, segundo o agressor (EL PAIS, 2016).

3 As entrevistas e a aplicação dos questionários foram realizadas nos meses de maio e julho de 2017.

4 Programa Nacional de Acesso ao Ensino Técnico e Emprego.

5 Na América Latina, o país pioneiro na transferência de escolas públicas para gestão privada foi o Chile durante a ditadura de Augusto Pinochet (1973-1990), em pleno processo de privatização de todos os serviços públicos.

6 Regular em tempo parcial; regular integral; Pro-EMI; técnico profissional; técnico integrado. 